Check for updates

Cite this: RSC Adv., 2018, 8, 25248

Received 24th April 2018

Accepted 3rd July 2018

DOI: $10.1039 / \mathrm{c} 8 \mathrm{ra0} 3506 \mathrm{~g}$

rsc.li/rsc-advances

\title{
Framework of ruthenium-containing nickel hydrotalcite-type material: preparation, characterisation, and its catalytic application $\uparrow$
}

\author{
Sreenavya A., ${ }^{a}$ Baskaran T., ${ }^{a}$ Ganesh V., ${ }^{b}$ Sharma D., ${ }^{c}$ Nagendra Kulal ${ }^{d}$ \\ and Sakthivel A. (ID*a
}

\begin{abstract}
The framework ruthenium-containing nickel (NiRu) hydrotalcite (HT)-type materials were prepared by a coprecipitation method for the first time in this study. Fourier-transform infrared spectroscopy and X-ray diffraction analysis revealed the formation of a layered hydrotalcite-type phase. DRUV-Vis and X-ray photoelectron spectroscopic studies revealed the presence of nickel in the +2 and +3 oxidation states along with the presence of ruthenium as $\mathrm{Ru}^{3+}$ ions. Temperature-programmed desorption studies of the NiRu-HT-type materials indicated a two-stage reduction with a decrease in $T_{\max }$, supporting the presence of $\mathrm{Ni}^{2+}$ and $\mathrm{Ru}^{3+}$ in the framework of hydrotalcite. The obtained NiRu-HT-type materials proved to be promising catalysts for the reduction of aromatic nitro compounds in the presence of hydrazine as a hydrogen source under ambient conditions. The NiRu-HT-type material demonstrated enhanced activity and selectivity during the reduction of nitrobenzene and its derivatives due to the synergistic effect of nickel and ruthenium ions.
\end{abstract}

\section{Introduction}

Anionic clays or hydrotalcite (HT)-like layered mixed hydroxides are natural or synthetic materials that are extensively used as adsorbents, ion-exchangers, ceramic precursors, flame retardants, stabilisers, corrosion inhibitors, and electrode materials and are employed in catalysis and pharmaceutical applications. ${ }^{1,2}$ These crystalline materials consist of positively charged two-dimensional sheets with water and exchangeable chargebalancing anions in the interlayer region. The general formula of the materials is $\left[\mathrm{M}^{2+}{ }_{1-x} \mathrm{M}^{3+}{ }_{x}(\mathrm{OH})_{2}\right]^{x+}\left(\mathrm{A}_{x / n}{ }^{n}\right) \cdot m \mathrm{H}_{2} \mathrm{O}$, where $\mathrm{M}^{2+}$ and $\mathrm{M}^{3+}$ respectively represent divalent and trivalent cations, $\mathrm{A}$ is the interlayer anion with charge $n$, and $x$ is the fraction of trivalent cations. ${ }^{3}$ The structure of HT-like compounds is similar to that of layered brucite, where $\mathrm{Mg}^{2+} / \mathrm{Al}^{3+}$ ions are located on octahedral $\left(\mathrm{O}_{\mathrm{h}}\right)$ co-ordination sites and share edges to form infinite sheets. The infinite sheets are stacked on each

${ }^{a}$ Department of Chemistry, School of Physical Sciences, Central University of Kerala, Kasaragod 671316, Kerala, India. E-mail: sakthiveldu@gmail.com

${ }^{b}$ Electrodics and Electro Catalysis Division, CSIR-Central Electrochemical Research Institute (CSIR-CECRI), Karaikudi 630003, India

'Department of Chemistry, University of Delhi, Delhi 110007, India

${ }^{d}$ Materials Science Department, Poornaprajna Institute of Scientific Research, Bidalur Post, Devanahalli, Bengaluru-562164, India

$\dagger$ Electronic supplementary information (ESI) available: Fig. S1 wide scan XPS spectra of (a) $\alpha-\mathrm{Ni}(\mathrm{OH})_{2}$, and (b) NiRu-0.2; Table S1 nitrobenzene reduction using a series of nickel based hydrotalcite; Scheme S1 representative reaction pathway of nitrobenzene reduction on nickel based hydrotalcite. See DOI: 10.1039/c8ra03506g other to form a positively charged framework, and the electrical neutrality is maintained by anions located in the interlayer domains containing water molecules. ${ }^{4,5}$ HT materials have also proved to be promising catalysts in a wide range of organic reactions, such as reduction, oxidation, alkylation, condensation, hydroxylation, transesterification, isomerisation, epoxidation, hydro-isomerisation, and reforming. ${ }^{3-5}$ These materials have advantages such as improved activity, selectivity, less waste production, and easy recovery of products. These materials can be used either in the as-synthesised form or in the form of mixed metal oxides derived after calcination. ${ }^{1-4,6-14}$ These types of layered HT materials possess inherent basicity and have redox properties, which are derived from the elemental composition of the octahedral layers of the materials. Catalytic properties of HTs can be modified by introducing varying divalent and trivalent cations such as $\mathrm{Zn}^{2+}, \mathrm{Ni}^{2+}, \mathrm{Mn}^{2+}, \mathrm{Co}^{2+}$, $\mathrm{Fe}^{2+}, \mathrm{Cr}^{3+}, \mathrm{Fe}^{3+}, \mathrm{Mn}^{3+}, \mathrm{Co}^{3+}$, and $\mathrm{Ga}^{3+}$ into the framework. Moreover, the properties can be modified by introducing anions like halides, carbonates, nitrates, sulphates, silicates, organic anions, anionic complexes, or anionic polymers in the interlayer region. ${ }^{15-22}$

In recent decades, the transition-metal-based HT-like system has gained increasing interest among researchers because of its enormous applications in the field of reforming, fine chemicals, and redox processes. ${ }^{3-5}$ A nickel-based material is one among the most widely used transition metal and has a strong ability to form a bimetallic system with other trivalent metal ions. Nickelbased HT was developed because it is easily available, low-cost alternative to noble metal catalysts, has electronic properties 
similar to noble metals, and has an excellent activity for various elementary organic transformations and reforming processes. ${ }^{3-15}$ There are several studies on nickel-based HT-like catalyst for use in both fine, petro chemical and electrochemical processes such as catalytic reforming, dehydrogenation, hydrogenation, and electrocatalysis. ${ }^{23}$

In recent years, attention has been focussed on the preparation and applications of monometallic HT-like compounds in which a single element (transition metal ions) was used in both divalent and trivalent framework sites. The early work devoted to these types of materials was reported by Taylor in 1980 . Taylor studied the formation and properties of $\mathrm{Fe}^{2+} / \mathrm{Fe}^{3+}$ hydroxyl carbonates. Moreover, several studies were focused on the preparation of various monometallic, such as iron-, cobalt-, and nickel-based HT type compounds. These materials proved to be promising as catalysts, super-capacitors, electro-catalysts, biosensors, electro-chromic electrodes and optical devices, water treatment agents etc. $^{24-32}$

Monometallic nickel-based HT materials have potential applications in rechargeable batteries, photonic catalysis, and non-enzymatic glucose sensors. However, there are limited studies that discuss the catalytic applications of monometallic nickel-based HT materials. Moreover, these materials are often prepared in the presence of excess of organic anions and hexamethylenetetramine, which is a hydrolysing agent. Nickel was found to be active in a number of processes such as hydrogenation and reforming reactions. However, single component $\mathrm{Ni}$ catalysts cannot meet the activity, selectivity, and stability requirements in many processes at the industrial level. Nickel has a high alloying efficiency with noble metals and many transition metals. Therefore, nickel can be easily utilised to develop a catalyst with a diversified catalytic application. Currently, there are many studies on the facile fabrication of bimetallic nickel systems that present potential alternatives for noble metal catalysts, which are expensive, in terms of the catalytic activity and stability. ${ }^{23,33-42}$

Thus, it will be interesting to introduce a small amount of trivalent ruthenium ions, which possess excellent activity in various organic transformations such as hydrogenation, $\mathrm{C}-\mathrm{C}$ coupling, and metathesis, to the monometallic nickel HT-type materials. In this work, we intend to prepare HT-type $\alpha$ $\mathrm{Ni}(\mathrm{OH})_{2}$ containing ruthenium ions by using a simple coprecipitation method and used as a potential catalyst for the hydrogenation of nitro compounds to corresponding anilines. The hydrogenation of nitro-compound is one of the important industrial processes to produce aniline, which is used for the synthesis of polyurethane, dyes, pharmaceutical products and agricultural products.

\section{Experimental section}

Ruthenium-containing nickel (NiRu) HT-type material was synthesised by the co-precipitation method without using any organic base. Solution 1 was prepared by dissolving nickel nitrate $\left(\mathrm{Ni}\left(\mathrm{NO}_{3}\right)_{2} \cdot 6 \mathrm{H}_{2} \mathrm{O} ; 5 \mathrm{mmol}\right)$ and ruthenium chloride $\left(\mathrm{RuCl}_{3} \cdot 3 \mathrm{H}_{2} \mathrm{O} ; 1 \mathrm{mmol}\right)$. Solution 2 was prepared by dissolving ammonium carbonate $\left(\left(\mathrm{NH}_{4}\right)_{2} \mathrm{CO}_{3} ; 6 \mathrm{mmol}\right)$ and ammonium hydroxide $\left(\mathrm{NH}_{4} \mathrm{OH} ; 30 \mathrm{mmol}\right)$ in $40 \mathrm{ml}$ deionised water. Solution 2 was added in a drop-wise manner into solution 1 with constant stirring at $65^{\circ} \mathrm{C}$ for $2 \mathrm{~h}$. The precipitation was observed in HT with a final gel pH of 8.5, and the resulting solution was maintained for ageing for $18 \mathrm{~h}$. The precipitation of NiRu-HT gel was filtered and washed with deionised water. The material was dried overnight and represented as NiRu-HT catalysts. The samples were prepared by introducing varying molar ratios of $\mathrm{Ni}-\mathrm{Ru}$, that is, $1: 0.1,1: 0.2,1: 0.3,1: 0.45$, and $1: 0.6$, and were represented as NiRu-0.1, NiRu-0.2, NiRu-0.3, NiRu-0.45, and NiRu-0.6, respectively.

\section{Characterization}

Powder X-ray diffraction (Powder XRD) was performed to determine the bulk crystalline phases of the materials by using an $18 \mathrm{~kW}$ X-ray diffractometer (Rigaku, Japan) with $\mathrm{Cu}-\mathrm{K} \alpha$ radiation $(\lambda=1.54184 \mathrm{~A})$. The diffraction patterns were recorded in the $2 \theta$ range of $2-80$ with a scan speed of $0.5 \mathrm{~min}^{-1}$ and step size of 0.02. Fourier-transform infrared (FT-IR) spectra were obtained using the PerkinElmer Spectrum 2000 FTIR in the $400-4000 \mathrm{~cm}^{-1}$ range by using $\mathrm{KBr}$ pellets. Thermal decomposition of the samples was analysed using a thermal analyser (simultaneous thermal analyser 600, PerkinElmer). The morphology and size of the materials were analysed using SEM (Phillips Technai $\mathrm{G}^{2}$ T30 SEM) operated at $300 \mathrm{kV}$. Diffused reflectance UV-visible spectra were recorded at $200-800 \mathrm{~nm}$ by using a UV-visible spectrometer (PerkinElmer) with the help of $\mathrm{BaSO}_{4}$ as the reference. X-ray photoelectron spectra (XPS) of the catalysts were recorded by using a custom-built ambient pressure photoelectron spectrometer (Prevac, Poland) that was equipped with a VG Scienta's R3000HP analyser and a MX650 monochromator. ${ }^{27} \mathrm{~A}$ monochromatic Al-K $\alpha \mathrm{X}$-ray was generated at $450 \mathrm{~W}$ and used for measuring the XPS data of the above samples. Base pressure in the analysis chamber was maintained in the range of $2 \times 10^{-10}$ torr. The energy resolution of the spectrometer was set at $0.7 \mathrm{eV}$ at a pass energy of $50 \mathrm{eV}$. The binding energy (BE) was calibrated with respect to the $A u 4 \mathrm{~F}_{7 / 2}$ core level at $84.0 \mathrm{eV}$. The error in the reported $\mathrm{BE}$ values is within $0.1 \mathrm{eV}$. Elemental composition present in the final materials was determined using ICP-AES. The reducibility of the materials was determined by the temperature-programmed reduction (TPR) studies using BELCAT-M (JAPAN). The textural properties (BET surface area, BJH average pore volume) of the samples were derived from $\mathrm{N}_{2}$ sorption measurements carried out at $-196{ }^{\circ} \mathrm{C}$ out using physisorption analyser (BEL SORP II, Japan) after the samples were degassed at $150{ }^{\circ} \mathrm{C}$ for at least $8 \mathrm{~h}$ under $10^{-3}$ torr pressure prior to each run.

\section{Catalytic study}

The catalytic activities of the synthesised NiRu-HT- and monometallic Ni-HT-type materials were studied for the reduction of various aromatic nitro compounds by using isopropanol as the solvent and hydrazine hydrate as the reducing agent under optimum conditions. In a typical reaction, $0.1 \mathrm{~g}$ of catalyst was introduced into the reaction mixture with $10 \mathrm{mmol}$ of nitro compound, $20 \mathrm{mmol}$ hydrazine, and $20 \mathrm{ml}$ isopropanol. The 
reaction was studied at different reaction temperature and duration. The products of the reaction were analysed using gas chromatography (Clarus-680, Perkin Elmer) with the flame ionisation detector using an Elite-5 column.

\section{Result and discussion}

FT-IR spectra of $\mathrm{Ni}(\mathrm{OH})_{2}$ prepared with different reaction conditions are shown in Fig. 1, which is characteristics of $\alpha$ $\mathrm{Ni}(\mathrm{OH})_{2}$ and $\beta-\mathrm{Ni}(\mathrm{OH})_{2}$. The sharp vibrational band observed around 3200 to $3700 \mathrm{~cm}^{-1}$ (Fig. 1) is a characteristic of $\beta$ $\mathrm{Ni}(\mathrm{OH})_{2}$, which is prepared using $\mathrm{NaOH}$ and $\mathrm{Na}_{2} \mathrm{CO}_{3}$, and is similar to vibrational bands observed for the brucite structure. The sample prepared using $\mathrm{NH}_{4} \mathrm{OH}$ and $\left(\mathrm{NH}_{4}\right)_{2} \mathrm{CO}_{3}$ displayed a broad vibrational band between 4000 and $3000 \mathrm{~cm}^{-1}$. This band occurs due to the stretching mode of hydrogen-bonded hydroxyl groups that are present in the brucite-like layers having interlayer water molecules. The bending vibration of the interlayer water is reflected in the broad band and appears at $1612 \mathrm{~cm}^{-1} \cdot{ }^{43}$ FT-IR spectra of samples prepared with varying ruthenium concentrations are displayed in Fig. 2. The spectral data of the samples resemble the $\alpha-\mathrm{Ni}(\mathrm{OH})_{2}$ type, which support the formation of hydrotalcite type (NiRu-HT) layered material structure. A strong absorption peak that appeared at $1380 \mathrm{~cm}^{-1}$ corresponds to the asymmetric stretch mode of $\mathrm{CO}_{3}{ }^{2-}$ ions. The band at $1380 \mathrm{~cm}^{-1}$, with a weak shoulder at $1470 \mathrm{~cm}^{-1}$, occurred due to the splitting of the band because of the three vibrational modes of carbonate. The characteristic bands for the $\mathrm{M}-\mathrm{O}$ bond appear in the vibrational spectral region below $1000 \mathrm{~cm}^{-1}$. An additional sharp band that occurs in the $840 \mathrm{~cm}^{-1}$ region is due to the various lattice vibrations associated with metal hydroxide sheets. The absorption peaks at 413 and $693 \mathrm{~cm}^{-1}$ can be assigned to the $\mathrm{M}-\mathrm{O}$ and $\mathrm{M}-\mathrm{O}-\mathrm{M}$ vibrations in the layered structure. ${ }^{35,44,45}$

Powder XRD patterns of $\mathrm{Ni}(\mathrm{OH})_{2}$ prepared using sodium and ammonium-based sources are shown in Fig. 3. The samples prepared using the sodium-based source showed sharp and symmetrical reflections of (001), (100), (101), and (102) planes around $2 \theta$ values of $19,33,38$, and $51^{\circ}$ respectively; these

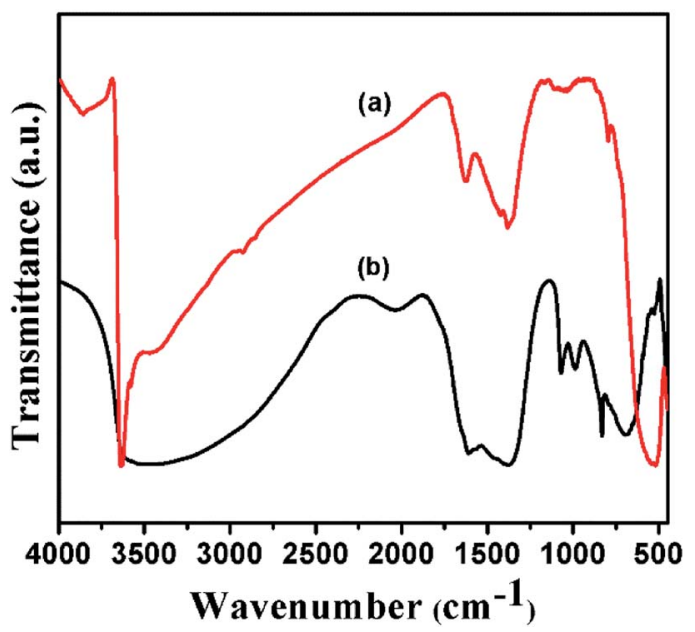

Fig. 1 FT-IR spectra of (a) $\beta-\mathrm{Ni}(\mathrm{OH})_{2}$ and (b) $\alpha-\mathrm{Ni}(\mathrm{OH})_{2}$.

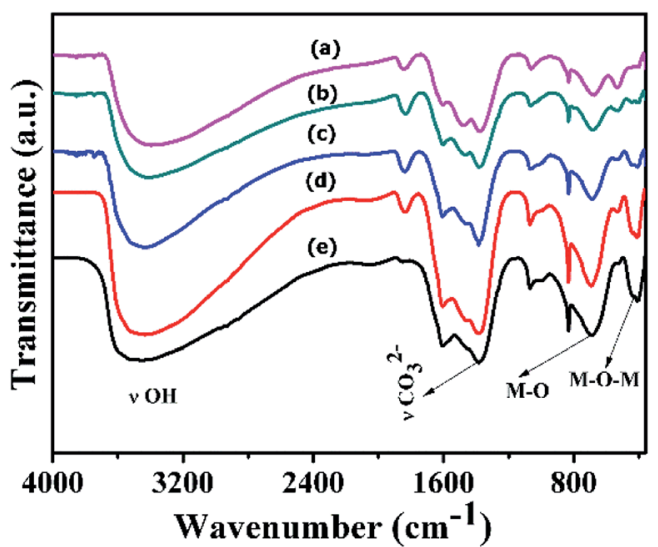

Fig. 2 FT-IR spectra of various NiRu-HT materials (a) NiRu-0.025 (b) NiRu-0.2 (c) NiRu-0.3 (d) NiRu-0.45 and (e) NiRu-0.6.

reflections typically belong to $\beta-\mathrm{Ni}(\mathrm{OH})_{2} \cdot{ }^{44}$ By contrast, the sample prepared using the ammonium-based source showed broad peaks at $2 \theta$ ranges $9.3,17.5,35$, and $60^{\circ}$ that correspond to (003), (006), (012), and (110) planes of the HT-type layered $\alpha$ $\mathrm{Ni}(\mathrm{OH})_{2}$, respectively. The broadening of X-ray reflection evidently supports the orientation of carbonate anion in the interlayer spaces of the brucite-type layered structure. Powder XRD patterns of NiRu-HT-type samples prepared with varying ruthenium ion concentrations are displayed in Fig. 4. The incorporation of $\mathrm{Ru}^{3+}$ ions in the framework of brucite-type layered $\alpha-\mathrm{Ni}(\mathrm{OH})_{2}$ facilitates the formation of layered HT-type structures, which is clearly evident from the powder X-ray patterns. All samples yielded X-ray diffraction (XRD) patterns with reflections at $2 \theta$ values of $4,6.23,18.23,34.23$, and $60.9^{\circ}$ that correspond to the (001), (003), (006), (012), and (110) planes of HT-type materials, respectively. ${ }^{37,38}$ Moreover, X-ray reflections corresponding to metallic ruthenium or any other oxide phases are not observed, which supports the formation of pure layered NiRu-HT-type materials.

TGA profile of $\alpha-\mathrm{Ni}(\mathrm{OH})_{2}, \beta-\mathrm{Ni}(\mathrm{OH})_{2}$, NiRu-HT are shown in Fig. 5. $\beta-\mathrm{Ni}(\mathrm{OH})_{2}$ displays a negligible weight loss of $0.355 \%$ due to the absence of any inter-layer physisorbed molecules (water,

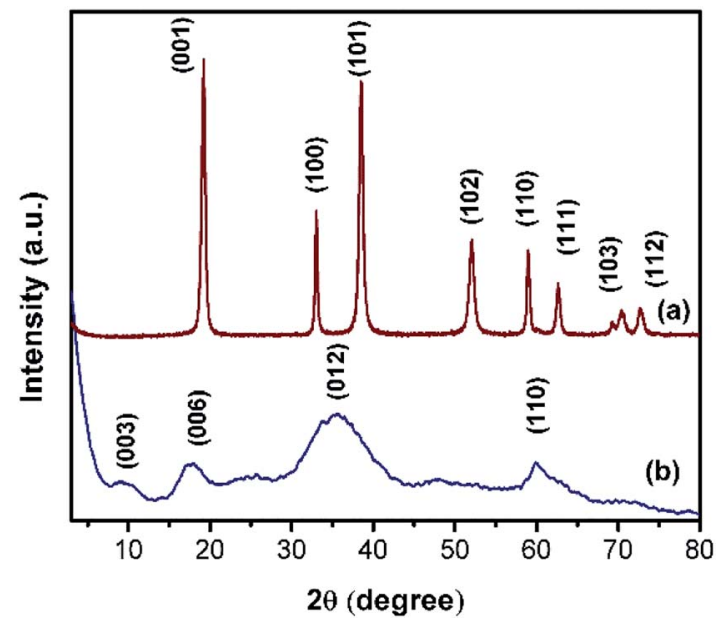

Fig. 3 Powder XRD patterns of (a) $\beta-\mathrm{Ni}(\mathrm{OH})_{2}$ and (b) $\alpha-\mathrm{Ni}(\mathrm{OH})_{2}$. 


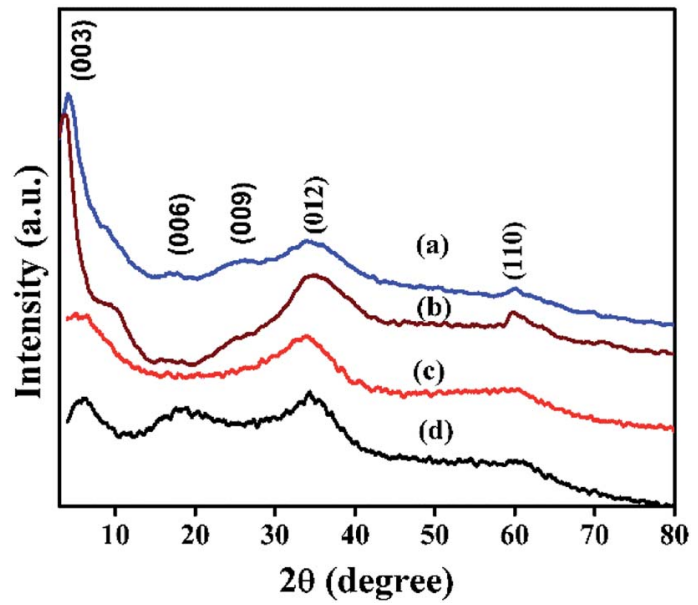

Fig. 4 XRD patterns of NiRu-HT samples viz., (a) NiRu-0.2 (b) NiRu-0.3 (c) NiRu-0.45 and (d) NiRu-0.6.

carbonate $e t c$.), which is in line with XRD analysis. The TGA profile of NiRu-HT-type materials exhibits a three-stage thermal decomposition. The first-stage weight loss of $15 \%$ occurs at a low temperature of approximately $120{ }^{\circ} \mathrm{C}$ is due to the elimination of physisorbed water molecules present in the inter-layer space. The second-stage weight loss is observed between 120 and $300{ }^{\circ} \mathrm{C}(20 \mathrm{wt} \%)$; this loss occurs due to the removal of chemisorbed water and carbonate anions from the internal and external surface of the HT-type structure. The last-stage weight loss $(15 \mathrm{wt} \%)$ occurs between 300 and $700^{\circ} \mathrm{C}$ and is attributed to the removal of hydroxyl groups from the brucite layers and interlayer carbonate anions in the form of $\mathrm{CO}_{2} \cdot{ }^{37}$

The co-ordination and oxidation status of the nickel species present in the structure were analysed using DR UV-Vis spectra, and the results are displayed in Fig. 6 . This figure reveals that $\alpha-$ and $\beta-\mathrm{Ni}(\mathrm{OH})_{2}$ samples show three absorption maxima in the wavelength region of 682,390 , and $238 \mathrm{~nm}$ that correspond to the following three spin-allowed, Laporte-forbidden transitions $\left({ }^{3} \mathrm{~A}_{2 g}(\mathrm{~F}) \rightarrow{ }^{3} \mathrm{~T}_{2 g}(\mathrm{~F}),{ }^{3} \mathrm{~A}_{2 g}(\mathrm{~F}) \rightarrow{ }^{3} \mathrm{~T}_{1 \mathrm{~g}}(\mathrm{~F})\right.$, and $\left.{ }^{3} \mathrm{~A}_{2 g}(\mathrm{~F}) \rightarrow{ }^{3} \mathrm{~T}_{1 \mathrm{~g}}(\mathrm{P})\right)$ of octahedral $\mathrm{Ni}^{2+}$ species. ${ }^{22}$ The introduction of a trace amount of ruthenium ions (NiRu-0.025-HT) in the framework of $\alpha-\mathrm{Ni}(\mathrm{OH})_{2}$

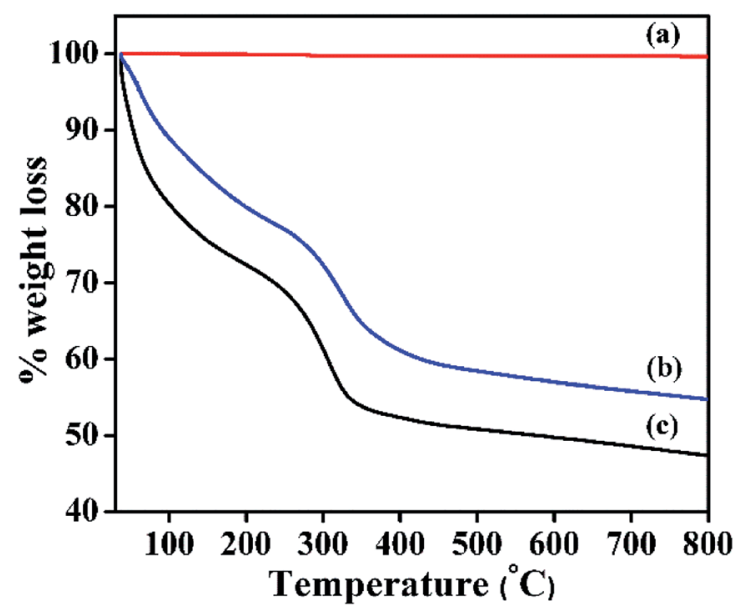

Fig. 5 TGA profile of (a) $\beta-\mathrm{Ni}(\mathrm{OH})_{2}$, (b) $\mathrm{NiRu}-0.2$, and (c) $\alpha-\mathrm{Ni}(\mathrm{OH})_{2}$.

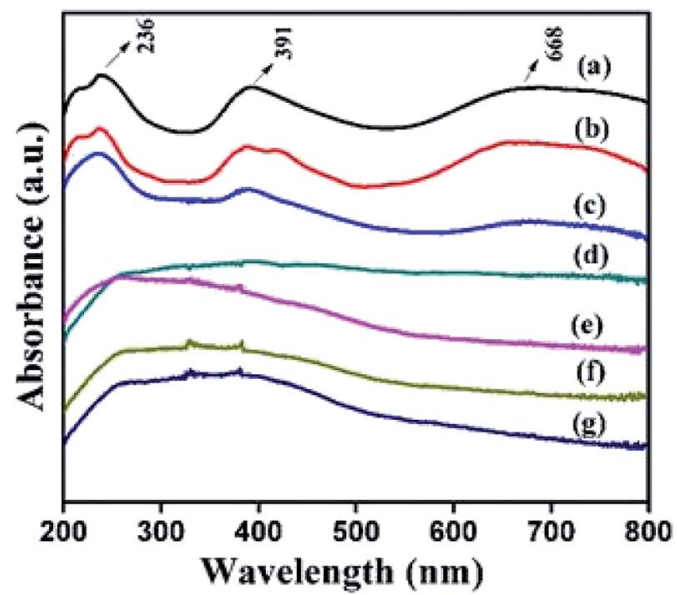

Fig. 6 DR UV-Vis spectra of (a) $\alpha-\mathrm{Ni}(\mathrm{OH})_{2}$, (b) $\beta-\mathrm{Ni}(\mathrm{OH})_{2}$, (c) NiRu0.025 (d) NiRu-0.2 (e) NiRu-0.3(f) NiRu-0.45 and (g) NiRu-0.6.

HT-type materials retains the absorption band correspond to dd transition of nickel ions. With an increase in the ruthenium ion concentration, the absorption band corresponding to higher energy transitions, that is, ${ }^{3} \mathrm{~A}_{2 g}(\mathrm{~F}) \rightarrow{ }^{3} \mathrm{~T}_{1 \mathrm{~g}}(\mathrm{~F})$ and ${ }^{3} \mathrm{~A}_{2 \mathrm{~g}}(\mathrm{~F})$ $\rightarrow{ }^{3} \mathrm{~T}_{1 \mathrm{~g}}(\mathrm{P})$, are not resolved and display a broad absorption band in the 200-500 $\mathrm{nm}$ region. This could be due to the overlap of intense bands that involve the delocalised $\mathrm{Ru}-\mathrm{O}$ molecular orbital for the $\mathrm{n}-\pi^{*}$ bands (465 $\mathrm{nm}$ ) derived from the framework of ruthenium ions and water coordinated octahedral $\mathrm{Ru}^{3+}$ ions. ${ }^{46}$ The absorption band corresponding to ${ }^{3} \mathrm{~A}_{2 g}(\mathrm{~F}) \rightarrow{ }^{3} \mathrm{~T}_{2 g}(\mathrm{~F})$ transitions disappears as the $\mathrm{Ru}$ concentration increases. The peak position of NiRu-HT-type samples indicates a blue shift when ruthenium ions are added to the materials, thus the alloying of Ni-Ru occurs. ${ }^{22,46,47}$

Table 1 summarises the elemental composition of NiRu-HTtype materials obtained from ICP-AES studies. The table reveals that the increase in ruthenium ions concentration in the final molar composition with an increase in the molar composition of synthesis gel was evident. The above fact supports that the introduced ruthenium ions are incorporated in the frame work of HT.

Fig. 7 shows the nitrogen sorption isotherms of $\alpha-\mathrm{Ni}(\mathrm{OH})_{2}$, NiRu-0.2 and NiRu-0.2-used (NiRu-0.2U) samples at $77 \mathrm{~K}$. The BET surface area of NiRu- 0.2 is $278 \mathrm{~m}^{2} \mathrm{~g}^{-1}$ which is comparable that of pure $\alpha-\mathrm{Ni}(\mathrm{OH})_{2}\left(318 \mathrm{~m}^{2} \mathrm{~g}^{-1}\right)$.

The isotherm of pure $\alpha-\mathrm{Ni}(\mathrm{OH})_{2}$, doesn't shown any significant uptake in mesoporous range, indicates the interparticle space is not available, which is further supported by BJH pore volume of $0.111 \mathrm{~cm}^{3} \mathrm{~g}^{-1}$. The isotherm curve of NiRu-0.2

Table 1 ICP-AES analysis of NiRu-HT type materials

\begin{tabular}{|c|c|c|c|c|}
\hline \multirow[b]{2}{*}{ Sample details } & \multicolumn{2}{|l|}{$\mathrm{mol} \%$} & \multirow{2}{*}{$\begin{array}{l}\mathrm{Ni}+\mathrm{Ru} \\
\mathrm{mol} \%\end{array}$} & \multirow{2}{*}{$\begin{array}{l}\mathrm{Ru} /(\mathrm{Ni}+\mathrm{Ru}) \\
\mathrm{mol} \%\end{array}$} \\
\hline & $\mathrm{Ni}$ & $\mathrm{Ru}$ & & \\
\hline NiRu-0.2 & 1.399 & 0.057 & 1.456 & 0.039 \\
\hline NiRu-0.3 & 1.343 & 0.085 & 1.428 & 0.059 \\
\hline NiRu-0.45 & 1.220 & 0.129 & 1.349 & 0.095 \\
\hline NiRu-0.6 & 1.080 & 0.159 & 1.231 & 0.128 \\
\hline
\end{tabular}




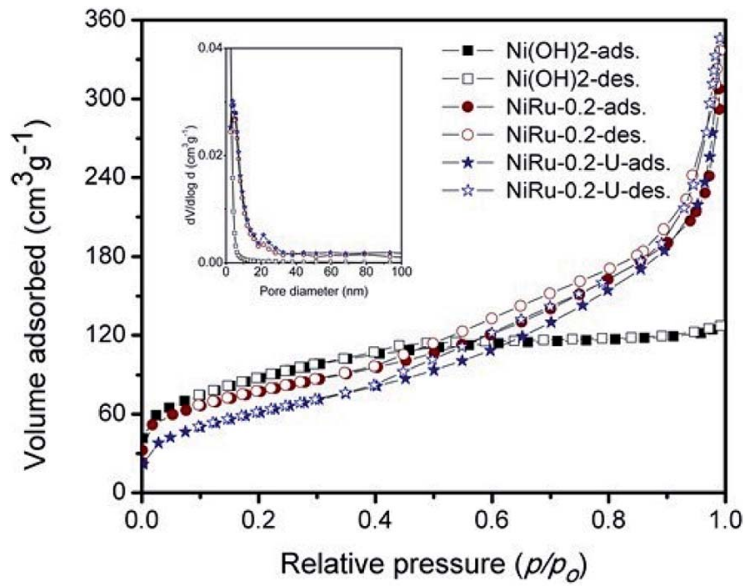

Fig. 7 Nitrogen sorption isotherm of $\alpha-\mathrm{Ni}(\mathrm{OH})_{2}$ and NiRuHT-0.2 before and after use.

exhibited multilayer adsorption (Fig. 7) in the relative pressure $\left(p / p_{\mathrm{o}}\right)$ range of $0.3-0.9$ are characteristics of type IV isotherms (Fig. 7) as per IUPAC classification. ${ }^{\mathbf{8} 9}$ The increase in pore volume of NiRu-0.2 sample (Table 2) along with observed type IV isotherm with $\mathrm{H} 4$ hysteresis indicating the presence of narrow slit-like interparticle mesoporous nature, which is evident from pore size distribution (Fig. 7 inset). The used catalyst (NiRu-0.2$\mathrm{U}$ ) showed similar isotherm characters, and surface area, pore volume and pore diameter (Table 2) clearly support that the samples remain intact even after several catalytic studies.

The SEM image of NiRu-0.2 HT is shown in Fig. 8. The catalyst surface consists of particles with irregular shapes and was formed due to the aggregation of individual particles. The sample displays individual particles in nano-size, which is in accordance with the reflection characteristics displayed in the XRD pattern.

Surface composition and oxidation states associated with the synthesised materials were characterised by X-ray photoelectron spectroscopy and the results are summarised in Table 3 . The wide scan of XPS spectra is available in ESI $\dagger$ (Fig. S1 $\dagger$ ). These studies are carried out to understand the nature of the active species present on the surface of NiRu-HT-type materials ( $\mathrm{Ni}$ HT, NiRu-0.2, and NiRu-0.6). Ni 2p core level spectra of these samples are shown in Fig. 9. The $\alpha-\mathrm{Ni}(\mathrm{OH})_{2}$ spectrum consists of a main peak of $\mathrm{Ni} 2 \mathrm{p} 3 / 2$ at the binding energy value of $855.5 \mathrm{eV}$ and a broad satellite at $860.9 \mathrm{eV}$. The Ni $2 \mathrm{p} 1 / 2$ peak is located at the binding energy value of $873.3 \mathrm{eV}$ with a satellite peak at 879.6. The main peak with broad satellite structure located within this binding energy range is considered as the contribution of divalent nickel species present in $\mathrm{Ni}(\mathrm{OH})_{2}$ structure. $^{48,49}$

Table 2 Textural properties of $\alpha-\mathrm{Ni}(\mathrm{OH})_{2}$ and NiRuHT- 0.2 before and after use

\begin{tabular}{lllll}
\hline Sl no. & Sample details & $\begin{array}{l}\text { BET } \\
\left(\mathrm{m}^{2} \mathrm{~g}^{-1}\right)\end{array}$ & $\begin{array}{l}\text { BJH pore } \\
\text { volume }\left(\mathrm{cm}^{3} \mathrm{~g}^{-1}\right)\end{array}$ & $\begin{array}{l}\text { Mean pore } \\
\text { diameter }(\mathrm{nm})\end{array}$ \\
\hline 1 & $\alpha-\mathrm{Ni}(\mathrm{OH})_{2}$ & 318 & 0.111 & 2.43 \\
2 & NiRuHT-0.2 & 278 & 0.453 & 4.25 \\
3 & NiRuHT-0.2-used & 228 & 0.511 & 3.75
\end{tabular}

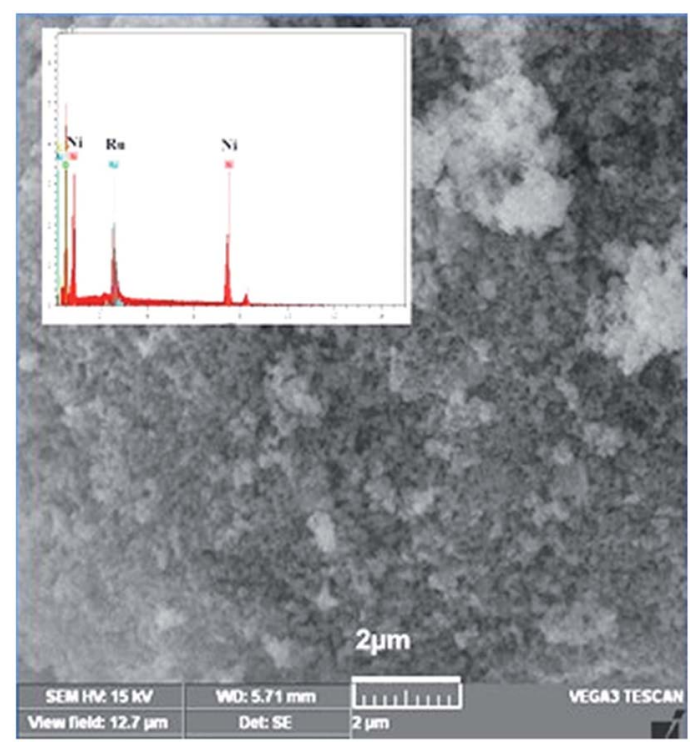

Fig. 8 SEM image of NiRu-0.2 HT.

The introduction of small amount of Ru in the frame work of $\alpha-\mathrm{Ni}(\mathrm{OH})_{2}$, for example NiRu-0.2 sample doesn't show much difference in the binding energy values, which supports the presence of $\mathrm{Ni}$ in identical environment in case of NiRu-0.2 as in $\alpha-\mathrm{Ni}(\mathrm{OH})_{2}$. In the case of $\mathrm{NiRu}-0.2$, the Ni $2 \mathrm{p} 3 / 2$ peak is located at the binding energy of $855.15 \mathrm{eV}$ with a satellite peak at $860.48 \mathrm{eV}$. The Ni 2p1/2 main peak is observed at the binding energy of $872.8 \mathrm{eV}$ with a satellite peak at $879.3 \mathrm{eV}$. These values are characteristics of nickel in +2 oxidation state with similar environment as of $\alpha-\mathrm{Ni}(\mathrm{OH})_{2}$. The introduction of large excess of $\mathrm{Ru}$ in the framework of $\alpha-\mathrm{Ni}(\mathrm{OH})_{2}$, viz., NiRu-0.6 sample shows a shift in the peak towards higher binding energy values. The binding energy observed for NiRu-0.6 such as $856.2 \mathrm{eV}$ with a satellite at $861.8 \mathrm{eV}$ for $\mathrm{Ni} 2 \mathrm{p} 3 / 2$ peak and at $873.8 \mathrm{eV}$ with a satellite at $880.17 \mathrm{eV}$ for Ni 2p1/2 peak. The shift in binding energy may be due to the contribution of trivalent nickel species that also exists in the layered structure. ${ }^{50}$ The increased concentration of ruthenium induces the nickel species to exist in higher oxidation state, i.e. +3 .

The XPS spectrum corresponding to $\mathrm{Ru} 3 \mathrm{p}$ of NiRu-0.2 showed (Fig. 10A) well distinguished two peak with the binding energies of Ru 3p3/2 and Ru 3p $1 / 2$ core level at $462.9 \mathrm{eV}$ and $485.04 \mathrm{eV}$ respectively, which are characteristics of ruthenium species in the trivalent $\left(\mathrm{Ru}^{3+}\right)$ oxidation state. ${ }^{51,52}$ On the other hand NiRu-0.6 exhibited peaks at the binding energy of $464.5 \mathrm{eV}$ and $485.58 \mathrm{eV}$ corresponding to $\mathrm{Ru} 3 \mathrm{p} 3 / 2$ and $\mathrm{Ru} 3 \mathrm{p} 1 / 2$ respectively, indicating the existence of ruthenium in the hydrated hydroxy form in the trivalent oxidation state. ${ }^{53}$

Interestingly $\mathrm{Ru} 3 \mathrm{~d} 3 / 2$ peak (Fig. 10B) of both NiRu- 0.2 and NiRu-0.6 sample is located at the binding energy value of $284.8 \mathrm{eV}$ suggesting the presence of ruthenium oxide in the hydrated form with in the frame work of nickel hydrotalcite. The incorporation of a large amount of ruthenium ions ( $\mathrm{NiRu}-$ 0.6) caused the broadening of XPS spectrum; this broadening may be attributed to the presence of some multiple oxidationstate ruthenium species. ${ }^{53}$ 
Table 3 XPS data of $\alpha-\mathrm{Ni}(\mathrm{OH})_{2}$ and $\mathrm{NiRu}-\mathrm{HT}$ materials

\begin{tabular}{|c|c|c|c|c|c|c|c|c|c|c|c|}
\hline \multirow[b]{2}{*}{ Catalysts } & \multicolumn{2}{|c|}{ Ni 2p3/2 (eV) } & \multicolumn{2}{|c|}{ Ni 2p1/2 (eV) } & \multirow{2}{*}{$\begin{array}{l}\text { Spin orbital } \\
\text { splitting }(e v)\end{array}$} & \multicolumn{2}{|c|}{$\begin{array}{l}\text { \& satellite } \\
\text { peak (eV) }\end{array}$} & \multirow[b]{2}{*}{ O 1s (eV) } & \multicolumn{2}{|c|}{$\mathrm{Ru}(\mathrm{eV})$} & \multirow[b]{2}{*}{$\mathrm{Ru} 3 \mathrm{~d}(\mathrm{eV})$} \\
\hline & Main & Satellite & Main & Satellite & & $2 \mathrm{p} 3 / 2$ & $2 \mathrm{p} 1 / 2$ & & $3 \mathrm{p} 3 / 2$ & $3 \mathrm{p} 1 / 2$ & \\
\hline$\alpha-\mathrm{Ni}(\mathrm{OH})_{2}$ & 855.50 & 860.90 & 873.30 & 879.6 & 17.80 & 5.90 & 6.90 & 530.6 & - & - & - \\
\hline NiRu-0.2 & 855.15 & 860.48 & 872.80 & 879.3 & 17.65 & 5.33 & 6.50 & 530.6 & 462.9 & 485.04 & 284.8 \\
\hline NiRu-0.6 & 856.20 & 861.80 & 873.8 & 880.17 & 17.47 & 5.60 & 6.23 & 531.7 & 464.5 & 485.58 & 284.8 \\
\hline
\end{tabular}

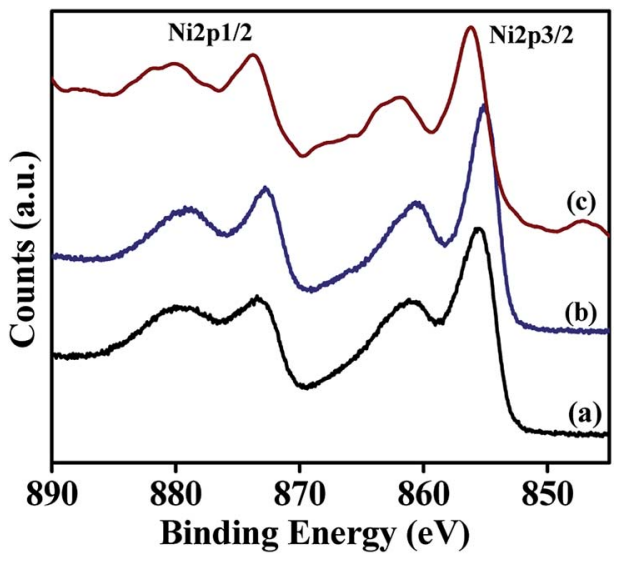

Fig. 9 XPS of Ni $2 p$ in various HT materials: (a) $\alpha-\mathrm{Ni}(\mathrm{OH})_{2}$ (b) $\mathrm{Ni}-\mathrm{Ru}-$ 0.2 , and (c) Ni-Ru-0.6.

Moreover, the oxygen 1s spectra of $\alpha-\mathrm{Ni}(\mathrm{OH})_{2}$ and NiRu-0.2 exhibited (Fig. 11) a broad peak in the binding energy value of $530.6 \mathrm{eV}$ due to the presence of oxygen in different environments such as $\mathrm{M}-\mathrm{O}-\mathrm{M}, \mathrm{M}-\mathrm{OH}$ (where $\mathrm{M}=\mathrm{Ni} / \mathrm{Ru}$ ), $\mathrm{CO}_{3}{ }^{2-}$ and water species. In case of NiRu-0.6 HT, the oxygen 1s spectra shows a shift towards higher binding energy (531.7 eV), which may be due to the formation of higher oxides in presence of increased amount of ruthenium. ${ }^{51}$ These results also correlate with our observations in $\mathrm{Ru} 3 \mathrm{~d}$ region of the samples.

The redox properties of $\alpha$ - and $\beta$-Ni(OH $)_{2}$ and NiRu-HT-type samples were studied using TPR with hydrogen. TPR studies enable to understand the reducibility of the NiRu-HT-type materials. The TPR profiles (Fig. 12) displayed that the pure $\alpha$ $\mathrm{Ni}(\mathrm{OH})_{2}$ exhibited a single reduction peak at $378{ }^{\circ} \mathrm{C}$, which is a characteristic of the reduction of $\mathrm{Ni}(\mathrm{OH})_{2}$ to metallic $\mathrm{Ni}^{54}$ However, $\beta-\mathrm{Ni}(\mathrm{OH})_{2}$ exhibited two reduction peaks between 391 and $630{ }^{\circ} \mathrm{C}$. The additional peak that appeared at $630{ }^{\circ} \mathrm{C}$ may be due to the amorphous NiO present on the surface of $\beta-\mathrm{Ni}(\mathrm{OH})_{2} \cdot{ }^{55}$ The incorporation of $\mathrm{Ru}^{3+}$ ions in the framework of $\alpha-\mathrm{Ni}(\mathrm{OH})_{2}$, that is, NiRu-0.1-type materials, caused a peak at a low temperature of approximately $360{ }^{\circ} \mathrm{C}$ due to the reduction of $\mathrm{NiRu}(\mathrm{OH})_{x}$ to the corresponding metallic nickel species.

The TPR profile of NiRu-0.2 suggests the existence of two reduction peaks at 278 and $362{ }^{\circ} \mathrm{C}$ that may have occurred due to the well dispersed ruthenium in the frame work as $\mathrm{Ru}^{3+}$ ions.
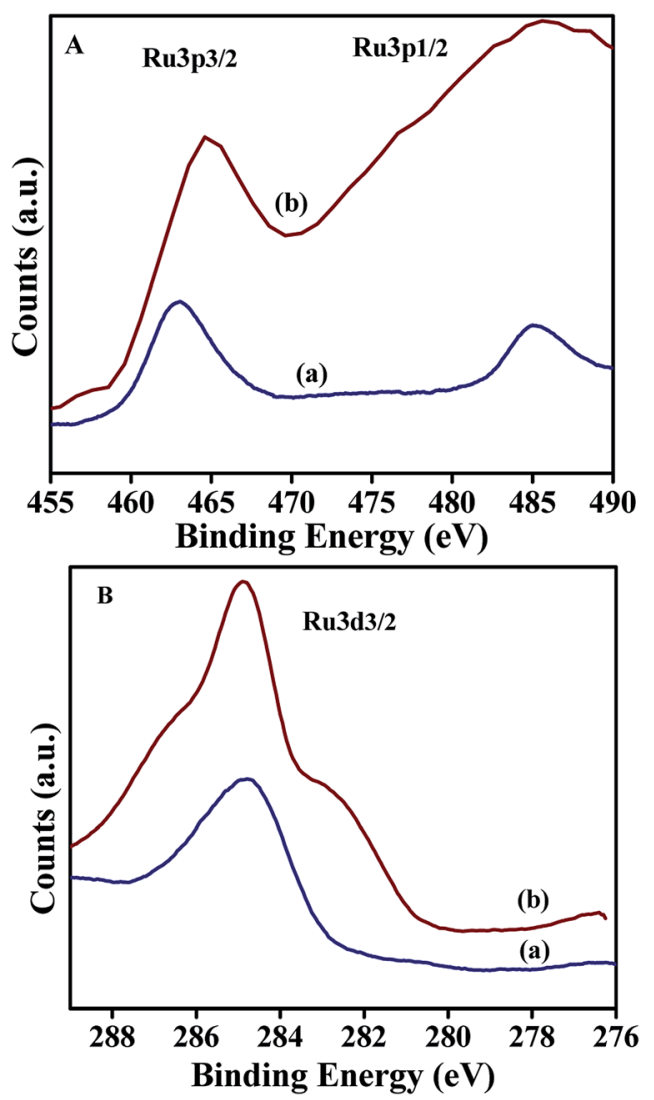

Fig. 10 XPS of (A) Ru 3p; (B) Ru 3d in (a) NiRu-0.2 and (b) NiRu-0.6.

The NiRu-0.6 sample exhibits reduction peaks at 290, 350, 416, and $568{ }^{\circ} \mathrm{C}$ respectively which could be due to presence of framework $\mathrm{Ru}^{3+}$ ions along with ruthenium oxide $\left(\mathrm{RuO}_{x}\right)$ and $\left(\mathrm{RuO}_{2}\right)$ species. ${ }^{55-57}$ As the $\mathrm{Ru}$ concentration increases in the samples, all TPR profiles of $\alpha-\mathrm{Ni}(\mathrm{OH})_{2}$ evidently shifted to lower temperature ranges. The decrease in the reduction temperature of nickel oxides is due to the presence of framework ruthenium ions, which have a role in hydrogen spill-over effect. ${ }^{56}$ The presence of ruthenium ions on the surface dissociates to hydrogen species which diffuses to the bulk materials and enables the reduction of NiRu-HT at lower temperature. ${ }^{\mathbf{5 8 , 5 9}}$ The lowering of the reduction temperature of NiRu-HT is due to the strong interaction between $\mathrm{Ni}^{2+}$ and $\mathrm{Ru}^{3+}$ ions in the framework of HT. 


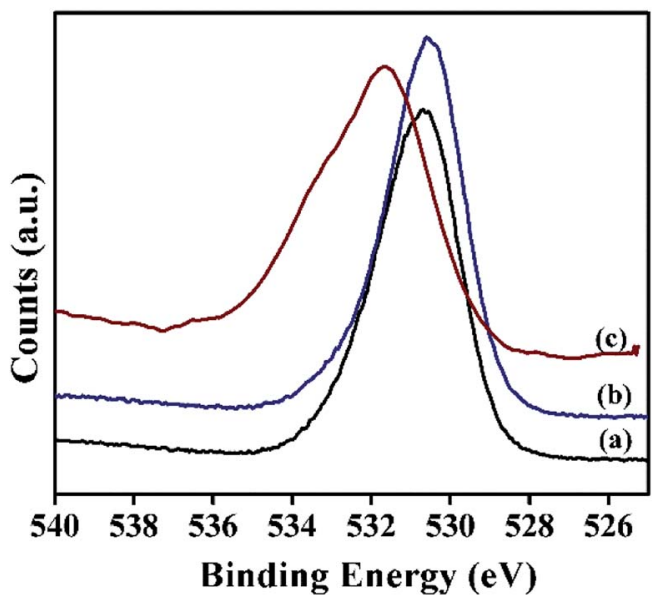

Fig. 11 XPS of $\mathrm{O}$ 1s in (a) $\alpha-\mathrm{Ni}(\mathrm{OH})_{2}$, (b) NiRu-0.2 and (c)NiRu-0.6.

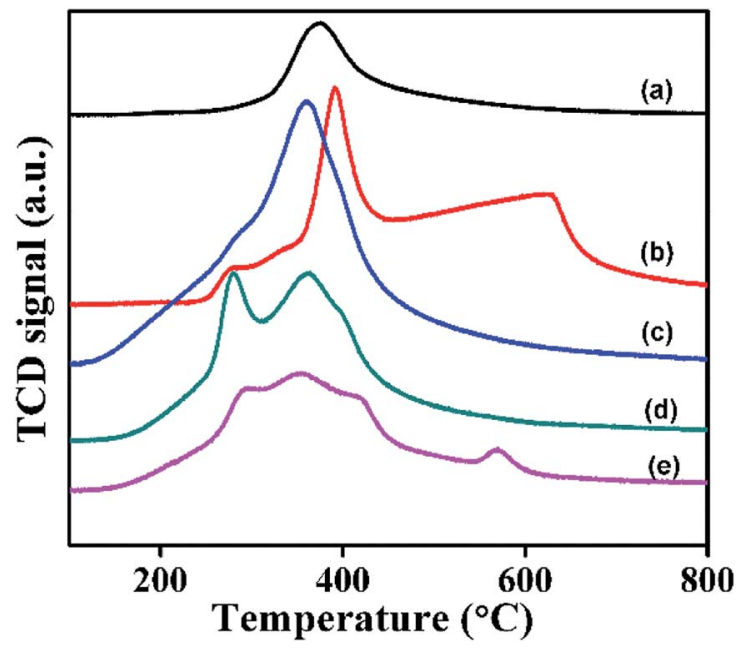

Fig. 12 TPR profile of (a) $\alpha-\mathrm{Ni}(\mathrm{OH})_{2}$ (b) $\beta-\mathrm{Ni}(\mathrm{OH})_{2}$ (c) $\mathrm{NiRu}-0.1$ (d) NiRu-0.2 and (e) NiRu-0.6.

\section{Influence of reaction parameters}

Influence of reaction temperature. Thoroughly characterized NiRu-HT-type materials were utilized for the catalytic conversion of nitrobenzene to aniline, and the results are summarized in the following section. In all the cases, aniline was obtained as major product with the formation of a considerable amount of azobenzene and azoxybenzene as by-products. Catalytic studies were conducted using the NiRu-0.2 sample at varying temperatures, and the results are shown in Fig. 13. Even at a very low temperature, the catalyst facilitates the complete conversion of nitrobenzene with the formation of a considerable amount of azoxybenzene and azobenzene. The formation of azoxybenzene and azobenzene is due to the reductive coupling of nitrobenzene under mild reaction conditions. As the temperature increases, the catalyst yields a higher quantity of aniline as the product, which might be due to the dissociation of the azocompound into aniline. The reaction doesn't proceed without a catalyst, which showed nitrobenzene conversion of below $1 \%$.

Influence of nature of the catalyst and catalyst loading. The catalytic activity of pure Ni-HT-type materials $\left(\alpha-\mathrm{Ni}(\mathrm{OH})_{2}\right)$

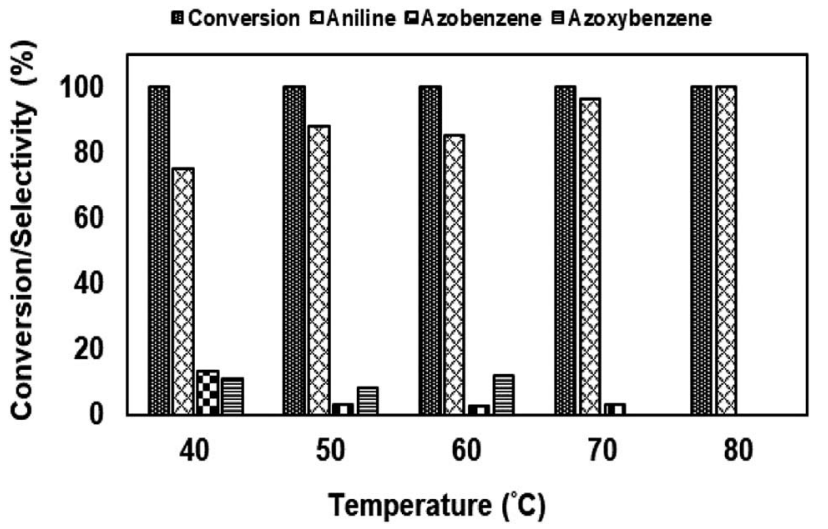

Fig. 13 Effect of the reaction temperature on nitrobenzene reduction using NiRu-0.2. ${ }^{\#}$ Conditions: nitrobenzene-10 mmol, hydrazine: $20 \mathrm{mmol}$, solvent-isopropyl alcohol (20 ml), catalyst (NiRu-0.2-(100 mg)).

further studied and results are shown in Fig. 14, which displayed only $35 \%$ conversion and $23 \%$ aniline selectivity with the formation of both azobenzene and azoxybenzene as major products. As the concentration of ruthenium increased (Fig. 14), the catalytic conversion improved with the exclusive formation of aniline was evident. The presence of nickel ions in the $\alpha$ $\mathrm{Ni}(\mathrm{OH})_{2}$ facilitates formation of azoxy and azo compounds as the major products (see Scheme S1†). ${ }^{60}$ The introduction of ruthenium ions gradually improves the formation of aniline selectivity, which suggests that there is a synergic mechanism involved between nickel and ruthenium ions. The nickel ions present in the NiRu-HT facilitate to reduction of nitro compounds into nitroso and phenylhydroxylamine (Scheme $\mathrm{S} 1 \dagger),{ }^{60}$ subsequently, the ruthenium ions present in the framework of NiRu-HT helps on control release of hydrogen which favoured the complete conversion of above intermediate into corresponding amine. The best results are evident in NiRu-0.2 sample. Thus, for further studies, all reactions were conducted using NiRu-0.2 sample at $80{ }^{\circ} \mathrm{C}$ for $4 \mathrm{~h}$. The reactions were conducted by varying the catalyst loading in the range of $0.01-$ $0.1 \mathrm{~g}$ by using $10 \mathrm{mmol}$ of nitrobenzene in presence of isopropanol with $20 \mathrm{mmol}$ of hydrazine as the hydrogen source. The results are depicted in Fig. 15. The presence of a small

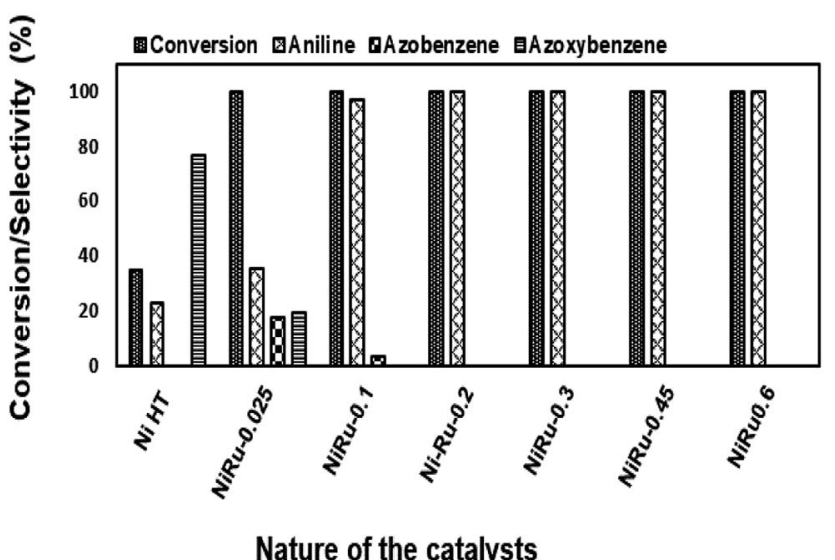

Fig. 14 Reduction of nitrobenzene using NiRu-HT catalysts prepared with different ruthenium concentration. 


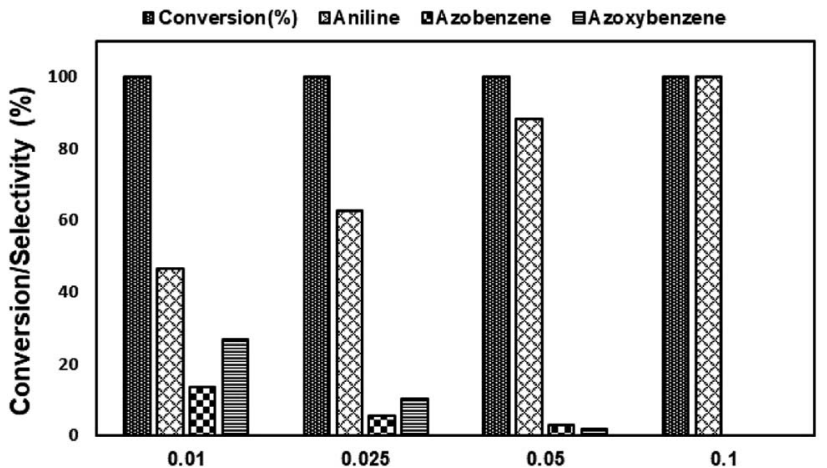

Amount of catalyst loading (g)

Fig. 15 Effect of catalyst loading on nitrobenzene reduction using $\mathrm{Ni}-$ $\mathrm{Ru}-\mathrm{HT}-0.2$.

quantity of catalyst facilitates the complete conversion of nitrobenzene. However, the formation of reductive coupling products such as azoxybenzene and azobenzene were evident when a low amount of catalyst was used. Exclusive formation of aniline was evident when $0.1 \mathrm{~g}$ of catalyst was used. For the comparison, a series of nickel based hydrotalcite such as NiRh, NiFe and NiCo catalysts were also prepared and utilized for the nitrobenzene reduction (Table $\mathrm{S} 1 \dagger$ ).

Among the various catalysts, the use of NiRu-0.2 facilitates the complete conversion with exclusive formation of aniline was evident. Under similar conditions, NiRh-0.2, NiFe-0.2 catalysts gave $100 \%$ nitro benzene conversion with $87.1 \%$ and $34.6 \%$ aniline selectivity respectively with the formation of azobenzene and azoxybenzene as by-products. NiCo- 0.2 catalyst shows only $16 \%$ conversion with $100 \%$ azoxybenzene selectivity. It is clear from above studies that among the various nickel based hydrotalcite, NiRu-0.2 catalyst is found to be superior for the complete conversion nitro benzene with the formation of aniline.

Recyclability study. To obtain the information on the stability of NiRu-HT catalyst, the spent catalyst was recycled by filtering from the reaction mixture, washing with isopropanol, and drying in an air oven. The catalytic activity of the recycled catalyst is summarised in Fig. 16. The complete catalytic conversion of nitrobenzene was evident even after four cycles. However, the gradual decrease in the selectivity may be due to the weight loss during catalyst recovery or may be due to the

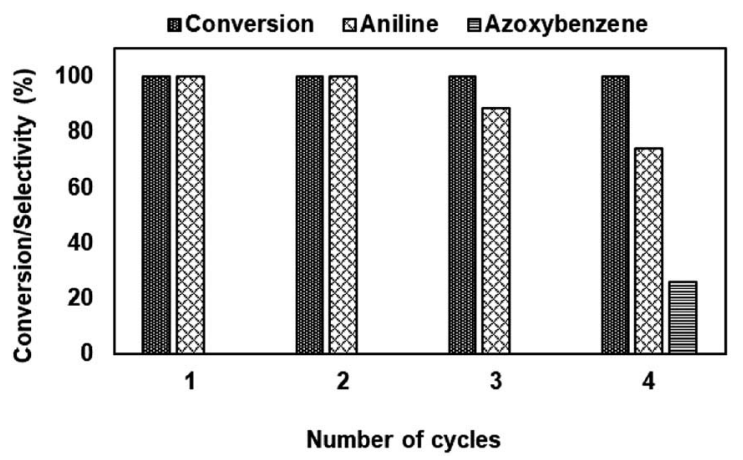

Fig. 16 Recyclability study of NiRu-0.2 catalyst. blockage of the pores of the catalyst due to the adsorption of products or reactants. The above fact was further supported from textural properties of used catalyst (Table 2).

Influence of substituent on nitrobenzene reduction. The catalyst was used for the hydrogenation of various substituted nitrobenzene under optimum reaction conditions, and the results are shown in Table 4 . A great variety of mono-substituted nitrobenzene has been reduced in optimal yields to the corresponding anilines with hydrazine hydrate in the presence of NiRu-HT- 0.2 catalyst at $80^{\circ} \mathrm{C}$ and at room temperature for $4 \mathrm{~h}$. It is observed that at $80{ }^{\circ} \mathrm{C}$ irrespective of the nature of the substitution and the position of the substitution on the substrate, the catalyst was found to efficiently reduce the substituted nitrobenzene into aniline with complete conversion and excellent selectivity towards the substituted aniline. The reaction studied using different substrate at room temperature yielded comparable conversion. The presence of electron donating group at para position facilitate better yield in amine products. The presence of electron with drawing group at para

Table 4 Reduction of various nitrobenzene using NiRu-0.2 material $^{a}$

\begin{tabular}{|c|c|c|c|c|}
\hline \multirow[b]{2}{*}{ Sl no. } & \multirow[b]{2}{*}{ Substrate } & \multirow[b]{2}{*}{ Product } & \multicolumn{2}{|c|}{ Yield (\%) at } \\
\hline & & & $35^{\circ} \mathrm{C}$ & $80^{\circ} \mathrm{C}$ \\
\hline 1 & & $\mathrm{H}_{2} \mathrm{~N}$ & 64 & 100 \\
\hline 2 & & & 39 & 100 \\
\hline 3 & & & 63 & 100 \\
\hline 4 & & & 55 & 100 \\
\hline 5 & & & 51 & 100 \\
\hline 6 & & & 37 & 100 \\
\hline 7 & & $\mathbf{H}_{2} \mathbf{N}$ & 87 & 91 \\
\hline 8 & & & 10 & 89 \\
\hline
\end{tabular}

${ }^{a}$ Substrate $(10 \mathrm{mmol})$, catalyst $\mathrm{Ni}-\mathrm{Ru}(1: 0.2),(100 \mathrm{mg})$, isopropyl alcohol $(20 \mathrm{ml})$, hydrazine hydrate $(20 \mathrm{mmol}=1 \mathrm{ml}), 80^{\circ} \mathrm{C}, 4 \mathrm{~h}$. 
position and electron donating group at meta position results in decrease in nitro-aromatic conversion. The presence of electron donating group at para position enhances the free electron density on nitro functional center which facilitates better yield of corresponding aniline. The substitution at ortho position does not show any trend, which might be due to steric influence. The studies well demonstrated that the NiRu-HT-type catalyst is promising for the reduction of aromatic nitrocompounds to corresponding aniline derivatives.

\section{Conclusion}

Ruthenium ions substituted on $\alpha$ - $\mathrm{Ni}(\mathrm{OH})_{2}$-type layered materials are prepared for the first time using a simple coprecipitation method without using organic base. The formation of layered hydrotalcite-type materials is evident from powder XRD studies. The presence of ruthenium ions in the HTframework is confirmed from powder XRD, XPS, and TPR studies. The presence of $\mathrm{Ni}^{2+}$ and $\mathrm{Ru}^{3+}$ in the octahedral environment is evident from the DRUV-Vis spectral studies. The presence of ruthenium ions in the framework facilitates the redox potential of catalysts employed for nitro-aromatic reduction, which showed a complete conversion of the nitro compound with exclusive formation of aniline products. Furthermore, the catalytic activity remains intact for several cycles.

\section{Conflicts of interest}

There are no conflicts to declare.

\section{Acknowledgements}

Authors thank to DST-SERB (EMR/2014/001214) for the financial support. Sreenavya is grateful to CUK for the fellowship and Lab facilities. Zeswa Catalyst Pvt. Ltd for their kind support on providing noble metal salts. Authors thank Dr G. V. Shanbhag, Poornaprajna Institute of Scientific research for their kind support on surface area analysis.

\section{Notes and references}

1 B. F. Sels, D. E. De Vos and P. A. Jacobs, Catal. Rev., 2001, 43, 443-488.

2 K. Ladewig, Z. P. Xu and G. Q. Lu, Expert Opin. Drug Delivery, 2009, 6, 907-922.

3 F. Cavani, F. Trifirò and A. Vaccari, Catal. Today, 1991, 11, 173-301.

4 T. Baskaran, J. Christopher and A. Sakthivel, RSC Adv., 2015, 5, 98853-98875.

5 A. Vaccari, Catal. Today, 1998, 41, 53-71.

6 T. Baskaran, J. Christopher, T. Ajithkumar and A. Sakthivel, Appl. Catal., A, 2014, 488, 119-127.

7 T. Baskaran, J. Christopher and A. Sakthivel, Adv. Porous Mater., 2014, 2, 54-60.

8 T. Baskaran, R. Kumaravel, J. Christopher and A. Sakthivel, RSC Adv., 2013, 3, 16392-16398.
9 T. Baskaran, R. Kumaravel, J. Christopher and A. Sakthivel, RSC Adv., 2014, 4, 11188-11196.

10 T. Baskaran, N. R. Mahato, J. Christopher and A. Sakthivel, Adv. Porous Mater., 2015, 2, 183-188.

11 A. Sakthivel, N. R. Mahato, T. Baskaran and J. Christopher, Catal. Commun., 2015, 65, 55-61.

12 D. Sharma and A. Sakthivel, J. Nanosci. Nanotechnol., 2018, 18, 381-385.

13 B. Thangaraj, C. Jayaraj, V. Ganesh and S. Ayyamperumal, Catal. Commun., 2016, 74, 85-90.

14 B. Thangaraj, C. Jayaraj, R. Srinivasan and S. Ayyamperumal, J. Mol. Catal. A: Chem., 2015, 409, 11-18.

15 W. T. Reichle, J. Catal., 1985, 94, 547-557.

16 K. Zhu, C. Liu, X. Ye and Y. Wu, Appl. Catal., A, 1998, 168, 365-372.

17 L. Yumin, L. Shetian, Z. Kaizheng, Y. Xingkai and W. Yue, Appl. Catal., A, 1998, 169, 127-135.

18 F. Bröcker and L. Kainer, UK Patent 1342020, 1971.

19 P. S. Kumbhar, J. Sanchez-Valente, J. M. M. Millet and F. Figueras, J. Catal., 2000, 191, 467-473.

20 Z. P. Xu, J. Zhang, M. O. Adebajo, H. Zhang and C. Zhou, Appl. Clay Sci., 2011, 53, 139-150.

21 O. Lebedeva, D. Tichit and B. Coq, Appl. Catal., A, 1999, 183, 61-71.

22 V. Rives and S. Kannan, J. Mater. Chem., 2000, 10, 489-495.

23 S. De, J. Zhang, R. Luque and N. Yan, Energy Environ. Sci., 2016, 9, 3314-3347.

24 C. Ruby, M. Usman, S. Naille, K. Hanna, C. Carteret, M. Mullet, M. François and M. Abdelmoula, Appl. Clay Sci., 2010, 48, 195-202.

25 D. Sharma, T. Baskaran, J. Christopher and A. Sakthivel, Nanosci. Nanotechnol. Lett., 2016, 8, 360-364.

26 X. Liu, R. Ma, Y. Bando and T. Sasaki, Angew. Chem., Int. Ed., 2010, 49, 8253-8256.

27 Z. Liu, R. Ma, M. Osada, K. Takada and T. Sasaki, J. Am. Chem. Soc., 2005, 127, 13869-13874.

28 P. Vialat, C. Mousty, C. Taviot-Gueho, G. Renaudin, H. Martinez, J. C. Dupin, E. Elkaim and F. Leroux, Adv. Funct. Mater., 2014, 24, 4831-4842.

29 B. Schneiderová, J. Demel, J. Pleštil, H. Tarábková, J. Bohuslav and K. Lang, Dalton Trans., 2014, 43, 1048410491.

30 K. Ariga, Y. Yamauchi, G. Rydzek, Q. Ji, Y. Yonamine, K. C.-W. Wu and J. P. Hill, Chem. Lett., 2013, 43, 36-68.

31 B. Zapata, P. Bosch, G. Fetter, M. Valenzuela, J. Navarrete and V. Lara, Int. J. Inorg. Mater., 2001, 3, 23-29.

32 D. Sharma, V. Ganesh and A. Sakthivel, Appl. Catal., A, 2018, 555, 155-160.

33 P. R. Martins, M. Aparecida Rocha, L. Angnes, H. Eisi Toma and K. Araki, Electroanalysis, 2011, 23, 2541-2548.

34 N. A. Hoque, P. Thakur, A. Kool, S. Das and P. P. Ray, J. Mater. Sci.: Mater. Electron., 2017, 28, 5375-5383.

35 D. S. Hall, D. J. Lockwood, C. Bock and B. R. MacDougall, Proc. R. Soc. A, 2015, 471, 20140792.

36 G.-X. Tong, F.-T. Liu, W.-H. Wu, J.-P. Shen, X. Hu and Y. Liang, Cryst. Eng. Commun., 2012, 14, 5963-5973. 
37 M.-Y. Cheng and B.-J. Hwang, J. Colloid Interface Sci., 2009, 337, 265-271.

38 J. W. Lee, J. M. Ko and J.-D. Kim, J. Phys. Chem. C, 2011, 115, 19445-19454.

39 Y. Luo, G. Li, G. Duan and L. Zhang, Nanotechnology, 2006, 17, 4278.

40 S. Cabanas-Polo, Z. Gonzalez, A. Sanchez-Herencia and B. Ferrari, Cryst. Eng. Commun., 2015, 17, 6193-6206.

41 Z. Gonzalez, J. Yus, A. Caballero, J. Morales, A. SanchezHerencia and B. Ferrari, Electrochim. Acta, 2017, 247, 333343.

42 D. Li, K. Nishida, Y. Zhan, T. Shishido, Y. Oumi, T. Sano and K. Takehira, Appl. Clay Sci., 2009, 43, 49-56.

43 S. Le Bihan and M. Figlarz, J. Cryst. Growth, 1972, 13, 458461.

44 M. Freitas, J. Power Sources, 2001, 93, 163-173.

45 F. M. Labajos, M. D. Sastre, R. Trujillano and V. Rives, J. Mater. Chem., 1999, 9, 1033-1039.

46 E. A. Seddon and K. R. Seddon, The Chemistry of Ruthenium, in Topics in Inorganic and General Chemistry: A Collection of Monographs, ed.R. J. H. Clark, Elsevier, 2013.

47 M. Krauss and W. Stevens, J. Chem. Phys., 1985, 82, 55845596.

48 M. Tomellini, J. Chem. Soc., Faraday Trans. 1, 1988, 84, 35013510.
49 A. P. Grosvenor, M. C. Biesinger, R. S. C. Smart and N. S. McIntyre, Surf. Sci., 2006, 600, 1771-1779.

50 A. Davidson, J. Tempere, M. Che, H. Roulet and G. Dufour, J. Phys. Chem., 1996, 100, 4919-4929.

51 K. Yamaguchi, T. Koike, J. W. Kim, Y. Ogasawara and N. Mizuno, Chem.-Eur. J., 2008, 14, 11480-11487.

52 D. Briggs and M. Seah, Practical Surface Analysis: By Auger and X-ray Photoelectron Spectroscopy, Wiley, 2003.

53 D. J. Morgan, Surf. Interface Anal., 2015, 47, 1072-1079.

54 J. Dou, Z. Bao and F. Yu, ChemCatChem, 2018, 10, 250-258.

55 A. Masalska, Catal. Today, 2008, 137, 439-445.

56 Z. Bian, S. Das, M. H. Wai, P. Hongmanorom and S. Kawi, ChemPhysChem, 2017, 18, 3117-3134.

57 A. S. Nagpure, A. K. Venugopal, N. Lucas, M. Manikandan, R. Thirumalaiswamy and S. Chilukuri, Catal. Sci. Technol., 2015, 5, 1463-1472.

58 A. Ballarini, P. Benito, G. Fornasari, O. Scelza and A. Vaccari, Int. J. Hydrogen Energy, 2013, 38, 15128-15139.

59 J. A. Velasco, C. Fernandez, L. Lopez, S. Cabrera, M. Boutonnet and S. Järås, Fuel, 2015, 153, 192-201.

60 M. Sudhakar, M. Lakshmi Kantam, R. Kishore, S. Naveen Kumar and A. Venugopal, Indian J. Chem., 2014, 53A, 550552. 